INTRODUCTION

\title{
Awake spinal surgery: where we are now and where we are going
}

\author{
Wilson Z. Ray, MD, ${ }^{1}$ Asdrubal Falavigna, MD, ${ }^{2}$ Praveen V. Mummaneni, MD, MBA, ${ }^{3}$ and \\ Robert C. Bucelli, MD, PhD4
}

1Department of Neurosurgery, Washington University School of Medicine, St. Louis, Missouri; 2Department of Neurosurgery, Caxias do Sul University, Caxias do Sul, Brazil; ' ${ }^{3}$ Department of Neurosurgery, University of California, San Francisco, California; and ${ }^{4}$ Department of Neurology, Washington University School of Medicine, St. Louis, Missouri

A WAKE spine surgery has increasingly been recognized as an attractive alternative to general anesthesia for many routine degenerative spinal procedures. This increased enthusiasm for awake surgery coupled with improved Enhanced Recovery After Surgery (ERAS) programs has provided an opportunity to further mitigate the potential complications associated with general anesthesia while still providing a durable solution for progressive spinal degenerative disease.

This issue of Neurosurgical Focus provides a global view of innovative and progressive contributions to the field of both ERAS and awake spinal surgery. As we traverse through an era of increased pressures to provide comprehensive care to patients who previously would not have been surgical candidates while simultaneously responding to the demand of patients seeking to return to normal activity with little to no down time, we must strive for a state-of-the-art solution that addresses this binary population with a singular solution. Awake spine surgery combined with novel anesthetic and pain management strategies can potentially bridge this gap.
The content provided in this issue of Neurosurgical Focus provides an important framework for where we have been, where we are, and where we are going with awake spinal surgery. Our ability to provide patients with individualized patient-centric care that minimizes risk and accelerates the return to "normal" will continue to be the catalyst for ongoing innovation and pressure us all to evolve.

https://thejns.org/doi/abs/10.3171/2021.9.FOCUS21565

\section{Disclosures}

Dr. Mummaneni: consultant for DePuy Synthes, Globus, and Stryker; direct stock ownership in Spinicity/ISD; royalties from DePuy Synthes, Thieme Publishers, and Springer Publishers; and non-study-related clinical or research effort from NREF, ISSG, AO Spine, and NIH. Dr. Ray: consultant for DePuy Synthes, NuVasive, Globus, Pacira, and Expanding Innovations.

\section{Correspondence}

Wilson Z. Ray: rayz@wustl.edu. 